\title{
A NATUREZA DA IMAGEM E A IMAGEM DA NATUREZA*
}

RAFAEL VOGT MAIA ROSA propõe relações da poética de Claudio Tozzi com a fotografia e o cinema

\begin{abstract}
(...) estou numa empreitada com gramas. Plantei uma grama aqui em frente de casa, num terreno público deteriorado, mas foi com sementes de grama bermuda (resistente). Uma aventura! Entrei literalmente na enxada. Acabei com minhas mãos, mas elas já se recuperaram, mas o mais incrível é que virei uma figura popular no bairro. Não tinha um que não comentasse, mas só quem me ajudou foi mesmo as crianças. Ainda há muito que fazer, esse barranco é terrível, cheio de entulho. Muita pedra, azulejo, que aos poucos eu vou retirando. O problema é que tem que ter um saco especial para colocar as pedras. E a grama demora três meses para vingar e tenho que acordar seis da manhã pra dar água, mas é uma bela tentativa.

Paulo Barroso (1969-2008)
\end{abstract}

Uma reportagem recente na Folha de S. Paulo estabelece uma comparação sumária entre a arte pop nos EUA e no Brasil, a partir da polarização entre uma perspectiva crítica da primeira e mais amena e condescendente da segunda. É raro não se citar Claudio Tozzi nessas sinopses e contextualizações e procurar ao menos uma característica que o distinga, por exemplo, do artista que a crítica em geral acaba por lhe considerar mais próximo, Roy Lichtenstein.

Entretanto, diferentemente do que ocorre no modernismo brasileiro, no caso de nossos artistas plásticos mais próximos à Pop Art, não se encontra um conceito como o da congenialidade para conseguir resumir toda uma produção a partir de uma mesma base de formação comum. E mesmo a ideia do "bárbaro tecnizado", se aplicada ao contexto do trabalho de Tozzi nos anos 60, a partir de uma aproximação "neo-antropofágica", não faz sentido no âmbito do uso que o artista faz da imagem técnica, o propósito central desse comentário sobre uma parte de sua produção nos anos 70 .

De todo modo, o traço distintivo da pop de Tozzi costuma ser relacionado à sua paleta de cor. Seus trabalhos da década de 60 seriam cromaticamente mais

*Capítulo da tese de doutorado de Rafael Vogt Maia Rosa Ensaios de uma dramaturgia Limiar (FFLCH/USP, 2012). 
afirmativos do que os de Lichtenstein ou Andy Warhol. Mas, ainda que algumas dessas obras apostem mesmo em cores primárias e possivelmente menos desajustadas em relação ao que preenchem, não se trata, ao que parece, nem de um cromatismo ingênuo, nem de um cromatismo crítico. A cor acaba por se mostrar simplesmente arbitrária, a ponto de acusar que há uma objetividade dada pelo uso da imagem técnica e dos signos oferecidos pela mídia de massa no âmbito das artes plásticas, como se restassem poucos elementos para serem subvertidos no que se refere à utilização de uma figura de H.Q. ou da própria bandeira norte-americana, por exemplo. E o depoimento retrospectivo do artista, na mesma reportagem mencionada, não dá muita margem para dúvida: "Eu trabalhava na época com os fatos do dia a dia. Eram imagens do Brasil, homenagens também."

Nesse ponto, a ambiguidade do título de uma obra como Desta Vez Eu Consigo Fugir parece mais eficaz do que o amarelamento do quadrante estrelado que aparece ao fundo da série Bandido da Luz Vermelha. Não é certamente a figura feminina que está fugindo do criminoso que, em outro quadro, ela teria conseguido abater com uma frigideira. Quer dizer, como fugir e do quê fugir, na realidade planar dada e problematizada pela cultura dominante? Que aspecto da técnica seria, nesse caso, de fato, subversivo?

Enfim, presumindo que não seja a cor, comenta-se uma cena do filme de Rogério Sganzerla, que, logo depois da série de Tozzi - foi lançado em 1968 - traz o mote desse mito urbano, inspirado em uma figura real, para a arte. O trecho que se destaca, permite pensar, literalmente, por meio da imagem técnica, a "transformação permanente do Tabu em totem" incitada por Oswald de Andrade[1], captando essa inversão a partir de uma alternância mágica, no contexto urbano da cidade de São Paulo. A sequência é exemplar: a Igreja da Consolação, uma das principais na região central da cidade, é filmada em um travelling vertical, de modo que vai diminuindo, desaparecendo em meio aos estacionamentos que a rodeiam. Ali, nesse lugar em que os emblemas e monumentos da cidade estão dissolvidos, a narração em off, midiática sensacionalista do filme, pontuada por juízos moralizantes e anacrônicos, pode ser interrompida a qualquer momento por cenas que mostram mulheres a caminho do trabalho levando malas que se abrem acidentalmente e deixam escapar cobras no meio da rua ou pela voz catastrofista de anões que profetizam em praças públicas, antes de serem "recolhidos" por autoridades: “O Terceiro Mundo vai explodir! Quem tem sapato não sobra!”

1. ANDRADE, Oswald de. "Manifesto Antropófago", in A Utopia Antropofágica. São Paulo: Globo, 1990, p. 48: "Tínhamos a justiça codificação da vingança. A ciência codificação da Magia. A transformação permanente do Tabu em totem.” 
Aqui surge a menção clara à uma estética de "empilhamento", que subverte a sintagmática dada pelos centros culturais hegemônicos. Cito Ismail Xavier:

\author{
É um universo social que tem no lixo seu emblema, tal como as operações \\ construtivas do filme da justaposição de resíduos, da incorporação \\ antropofágica de referências conflitantes a compor um quadro da \\ experiência do Terceiro Mundo como empilhamento de sucatas. O \\ Bandido descentra tudo, ostenta-se como filme periférico que focaliza uma \\ personagem periférica num mundo periférico.[2]
}

Mas a imagética de Tozzi não parece provir, exatamente, do lixo. Se considerarmos sua obra de 1969, o Astronauta, encontramos, no ponto mais alto do travelling vertical, um ser anódino, sem qualquer heroísmo ou humor, em primeiro plano. Há o destaque de um ícone tecnológico, um foguete, mas, nessa obra, a paisagem e a zona urbana já formam estratos pouco diferenciados que serão revistos pelo artista na década de 1970.

Essas apreciações iniciais são feitas para observar que, entre a série do Bandido e os trabalhos posteriores em que o artista se desloca de forma mais contundente em relação à estética pop, está o fato de ele operar com uma certa esterilização da figura não com intuitos formais, mas por uma demonstração de certa indiferença em relação ao inventário iconográfico, em prol da afirmação da dinâmica do meio que lhe traz à tona.

No trabalho de Tozzi parece importar menos o elemento enquadrado, a imagem apropriada, do que o ângulo de aproximação que o quadro mimetiza em relação à objetiva fotográfica e à câmera do cinema. E o que é ambiguidade em Revolta - porque a imagem remete de certo modo também a uma euforia de uma figura feminina diante de um pop star, por exemplo - transforma-se em um zoom radical em que mal se discerne o que é antropomórfico e o que é objeto industrial, em Homem ao telefone. Num outro limite "extraterrestre", o zoom ainda mais clínico em Mão do astronauta acaba por aproximar um conteúdo historicamente oposto, primitivo ou simplesmente animal. Ou seja, não parece ser um esforço compositivo, mas uma demonstração das possibilidades da pintura dialogar com a técnica em um plano discursivo que não escapa à ambiguidade e à contradição.

Assim, se a "fuga" operada por Sganzerla poderia ser emblematizada pelo vetor longitudinal, com amplas implicações no caso do cinema, seria possível arriscar

2. Cf. XAVIER, Ismail. O Cinema Brasileiro Moderno. São Paulo: Paz e Terra, 2001, p. 67. 
que a alternativa de Tozzi ocorre um vetor transversal muito próprio ao cinema e com implicações significativas para a pintura em nosso contexto. A passagem de Walter Benjamin é bastante conhecida:

\author{
O pintor observa em seu trabalho uma distância natural entre a realidade \\ dada e ele próprio, ao passo ao passo que o "cinegrafista" penetrar \\ profundamente as vísceras dessa realidade [câmera fotográfica]. As imagens \\ que cada um produz são, por isso, essencialmente diferentes. A imagem do \\ pintor é total, a do operador é composta de inúmeros fragmentos, que se \\ compõem segundo novas leis.[3]
}

No caso desses trabalhos de Tozzi, acrescenta-se a dificuldade de escanear e reproduzir os trabalhos, por uma ambiguidade que resiste na percepção do foco e resolução das reproduções. Como nas famosas cenas da ampliação, em que a personagem do fotógrafo do filme Blow Up (1966), de Michelangelo Antonioni, tenta, em vão, compreender o conteúdo de sua própria foto, o vetor oblíquo mostra a imagem técnica como um abismo de sentido, algo que, mesmo se enquadrado e ampliado, não se consegue decifrar ou que se renomeia para que se possa decifrar.[4]

A ambiguidade em relação às preocupações formais com o trabalho, confirmase até pelo anedotário aparentemente contrário à essa aproximação, envolvendo a obra Anywhere is my land (1968), de Antonio Dias - artista certamente muito próximo às questões da obras de Tozzi. No depoimento de Paulo Sergio Duarte, Dias fala de uma figuração endêmica que se dá na interpretação do espectador, frustrando a síntese improvável entre Pollock e Lichtenstein, no campo da pintura contemporânea. Cito:

3. BENAJMIN, Walter. “A Obra de Arte na Era de sua Reprodutibilidade Técnica”, in Op. Cit., p. 187.

4. JAMESON, Frederic. As Marcas do Visível, trad. Ana Lúcia de Almeida Gazolla et al. Rio de Janeiro: Graal, 1995, p. 200: "Das várias 'falhas' óbvias desse filme [Blow Up] ainda muito atual e vivo (pode-se ver por que Antonioni pensava que os mímicos e performers eram necessários, mas hoje essas imagens estão desgastadas), o problema formal principal, de natureza metafísica, se posso colocar dessa maneira, está ligado ao cadáver: será que ele deveria mesmo ter sido visto? A existência do referente deveria mesmo ter sido documentada desse modo 'realista ou representacional?" Essa parece ser uma questão importante para se ler aspectos espaciais do filme. Mencionamos também uma cena em que a questão da temporalidade da música e o problema da documentação de algo no lugar da representação parece bastante significativa até porque não provem da matriz literária do filme - diga-se de passagem, uma adaptação cinematográfica de conto de Julio Cortázar, As Babas do Diabo, lançado em 1959. Nela, o realismo frio do boneco de cera é contrastado com a presença no palco de músicos como Jeff Beck e Jimmy Page, que só poderiam estar representando a si mesmos ao tocarem uma versão da música Train Kept a Rollin' (1951) de Johnny Burnette. No desfecho da sequência, o ator David Hammings passa de espectador passivo e anônimo, a um membro que distingue-se na multidão por lutar com ela para possuir o braço da guitarra que o roqueiro acabou de destruir no palco - como já mandava o figurino. Logo que sai da casa de show, verifica o que tem em mãos não deixa de ser uma parte real de um instrumento musical, mas joga-o na rua em frente a uma vitrine com manequins femininos anódinos. Um garoto recolhe o objeto e torna a jogá-lo fora ao constatar sua inutilidade. 


\begin{abstract}
[Antonio Dias] Pintava as telas de preto e depois as salpicava de branco, numa experiência de, através da pintura, procurar a crítica pela 'representação da não-representação'. Depois mostrava essas telas a diversas pessoas: não adiantava, elas viam 'estrelinhas' [sic].[5]
\end{abstract}

As obras da série das Multidões de Tozzi são todas construídas a partir desse limite do reconhecimento, embora em uma escala mais urbana do que a de Dias. Elas mostram um processo em que não há possibilidade de síntese. Parte-se de um enquadramento que tem alguma centralidade, que distribui os elementos de modo hierárquico, narrativo. Mas o conjunto dissolve essa centralidade, aproxima-se ou mesmo distancia-se desses componentes figurativos, trazendo o que se chama no cinema de extracampo para o enquadramento da tela ou painel. O extracampo como núcleo da obra, como o preenchimento, mostra que de uma determinada distância contextual não é possível mais ler o signo. Cria-se um tipo de aglutinação que parece demonstrar a essência iconográfica da foto, no lugar hipótese de que seja indicial, mas que, ao mesmo tempo, mobiliza tudo na incongruência entre significantes e significado. E, de fato, mesmo em 1968, quem arriscaria dizer o que uma multidão simboliza, em uma única expressão?

A relação entre duas obras com uma sintaxe semelhante pode ser bastante ilustrativa: em Terceiro Mundo o conteúdo social seria mais evidente. Os trapos e outros elementos da moldura não operam uma lógica metonímica, da parte pelo todo. A moldura não fala sobre a multidão, mas sobre a dificuldade de leitura dos elementos quando eles estão comprimidos, entrouxados. Já no núcleo, em destaque, o amarelado e alaranjado que impregna as fotos de figuras masculinas "protestando" algo não seriam mais relativizantes que a repetição e mudança de ângulos utilizada na composição.

Em Poluição, é a reincidência do título em inglês, Third World e Polutions, que faz pensar em falsos cognatos visuais. O que se está emoldurando é de difícil depreensão. A poluição tem uma matéria mais palpável na moldura. No núcleo, tem-se um insumo para uma aproximação com as tautologias e ambiguidades anedóticas da Arte Conceitual. Pois, Retrato é justamente a entrada didática para esse campo, o embaralhamento programático, uma pré-entropia ilustrativa. Aqui se adianta uma releitura de aspectos menos específicos do Conceitualismo e um diálogo com tópicos da landart, de Robert Smithson, quase em clave paródica, mas não sem reiterar uma problemática local.

No caso de Smithson, haveria o que ele mesmo chamou de demonstrações

5. Antonio Dias em entrevista não publicada a Ivan Cardoso, citado por Paulo Sérgio Duarte em nota de rodapé do livro A Trilha da Trama e outros Textos sobre Arte, Luiza Duarte (org.), Rio de Janeiro: Funarte 2004, p. 31. 
ingênuas:

Agora eu gostaria de demonstrar a irreversibilidade da eternidade usando um experimento ingênuo para a verificação da entropia. Imagine-se a caixa de dividida pela metade, com areia preta de um lado e areia branca do outro. Tomemos uma criança e façamos com que ela corra pela caixa cem vezes no sentido horário até que a areia se misture e comece a ficar cinza; depois faremos com que ela corra no sentido contrário ao dos ponteiros do relógio e o resultado não será a restauração da divisão original, mas um acinzentado ainda maior e um incremento da entropia.[6]

O investimento no componente verbal é ostensivo. Já os trabalhos como os da série Interferência, de Tozzi, estão silenciosamente congelados no tempo, um pouco devedores do inventário em torno da universo da tecnologia, das viagens interplanetárias como elemento exógeno em relação à cultura brasileira. Mas há, como nos Monumentos de Smithson, uma eleição de sites inusitados como alvos para a combinação de foto e texto. No caso de Tozzi, reitera-se que o texto é bem mais econômico, surge apenas, em forma de uma teatralização, nos títulos que o espectador tem que interpretar.

Nas interferências de Tozzi, não deixa de haver uma minimização do componente formal, uma protuberância no terreno, uma fissura no solo, o tratamento cromático que investe gerando uma minificcionalização das imagens a partir, mais uma vez, da ambiguidade da distância que o olhar mantém em relação aos objetos e coisas. Esse componente local pode ser associado na relação do artista com a obra de Hélio Oiticica. Antes, porém, seria importante tentar verificar de que modo Tozzi foi dos artistas que assimilou de uma maneira praticamente literal as proposições de Oiticica sobre a natureza da imagem "obviamente brasileira", como uma injunção do urbano e paisagístico, natural e cultural, a imagem em Tropicália, instalação que tem um reflexo evidente na sala de Tozzi apresentada na Bienal de Veneza de 1976:

Em Tropicália criei uma espécie de cena tropical, com plantas, araras, areia, pedras, seixos, brita... o problema da imagem é posto aqui objetivamente - mas desde que o mesmo é universal, proponho também este problema num contexto que é tipicamente nacional, tropical e brasileiro (...). Mas as imagens em tropicália não podem ser consumidas, não podem ser apropriadas, diluídas ou usadas para intenção comerciais ou chauvinistas. Pois que o elemento de experiência direta vai além do problema de

6. SMITHSON, Robert. "Um Passeio Pelos Monumentos de Passaic, Nova Jersey" (1967), trad. Agnaldo Farias, Espaço \& Debates N. 43-44. São Paulo: Núcleo de Estudos Regionais e Urbanos - NERU, 2003, p. 128. 
imagem.[7]

Cito, agora, Tozzi, a partir de seu depoimento a Fabio Magalhães:

Realizei, também a partir de 1973, trabalhos sem uma referência específica à imagem, mas que continham, através de um conceito e da utilização de materiais diversos, a proposta de comunicar, de forma subjetiva, uma certa intenção que traduzisse a unidade do quadro. São trabalhos estruturados a partir do acoplamento de matérias em uma caixa de acrílico. A relação simbólica se dava pela matéria utilizada e não pela imagem. Utilizei fibra de algodão com pigmento, areia, terra natural com resina, grama seca em estufa e a cada material era associado um determinado significado, criando uma poética visual, quase um poema-objeto. O trabalho Grama/Terra/ Céu é uma superposição de quadrados a partir do ponto central, onde o encontro das diferentes matérias determina o seu contorno. E a cada matéria associa-se um significado. Estes trabalhos participaram da representação brasileira na Bienal de Veneza de 1976, e foram montados de modo a formar um ambiente, hoje, instalação. O Piso era composto por seixos de pedras, que escondiam uma camada líquida de essência de eucalipto. Ao entrar no espaço, o espectador sentia a textura do piso, o cheiro da essência, o visual dos quadros-objetos e construía a sua síntese de percepção ambiental.[8]

Chama-se a atenção para o cheiro da essência de eucalipto e para a transição inusitada do natural para o artificial, do paisagístico para o urbano, e também para o jogo entre falso e verdadeiro que parece resistir em todos esses trabalhos feitos a partir de 1973. O perfume pode ser qualificado, aqui, como um símbolo ou ao menos um signo em que há alguma motivação entre significante e significado. Ela ataca os sentidos de forma mais instantânea do que a imagem, como não poderia deixar de ser, e pode significar algo como: "cheiro de natureza", alta concentração de verde - o eucalipto quase como um mato gigante - amplificando inquestionavelmente outros cheiros mais amenos como o da terra ou da grama.[9] Essa essência, na instalação de Tozzi, é o que dá o contexto, um outro vetor de seu trabalho que seria o frame urbano para o imaginário ligado à natureza. Aqui, arrisca-se dizer que estamos próximos também ao universo dos textos de John Cage, em que a ideia de que o "significado é o uso" transcende qualquer separação entre real e ficcional: "Depois de mais ou menos uma hora nos bosques

7. OITICICA, Hélio. Aspiro ao Grande Labirinto, Luciano Figueiredo (Org.). Rio de Janeiro: Rocco, 1986, p. 144 (anexos não paginados).

8. MAGAlHÃES, Fabio (Org.). Claudio Tozzi. São Paulo: Lazuli Editora/cia editore nacional, 2007, p.42.

9. BORER, Alain. “Um Lamento Por Joseph Beuys”, in Joseph Beuys. Trad. Betina Bishof e Nicolás Campanário. São Paulo: Cosac Naify, 2001, pp. 11-34. 
procurando cogumelos, papai disse: 'Bem, sempre a gente pode ir comprar alguns verdadeiros"'.[10]

Com o perdão da analogia: não seria urbanidade de São Paulo vista sob as perspectivas paisagísticas do Rio de Janeiro; mas a natureza dada do Rio vista sob o plano construído de São Paulo, já que estamos distantes de um contraste como o que existe entre Manhattan e Passaic, algo que permitiu para Smithson uma ficcionalização de uma viagem de 50 minutos de ônibus como se esta fosse uma viagem a outro planeta.[11] Ou seja, os trabalhos contemplam o sentido pronto da proposição de Oiticica também no que se refere ao uso de terra e pigmentos in natura e outros, mas recondicionados como preenchimento, algo muito próximo, aliás, das operações suas feitas com a fotografia.

Do ponto de vista dos objetos, pinturas, em alguma instância, justamente por permanecerem no limite planar da imagem, por não subverterem os planos dados por condições físicas elementares, trata-se muito mais de uma imagem da natureza, nesse caso, algo dado facilmente, do que da natureza da imagem. São quadros que estabelecem um discurso bastante amplo, permitindo associações tanto com uma obra antológica como o Livro de Carne, de Artur Barrio, como com a série Construtivismo Rural de Nelson Leirner.

Vaca, de Tozzi, é um cruzamento oportuno para um comentário sobre esse discurso. No caso de Barrio, o artista mesmo chama a atenção para a questão do contexto determinando o significado: "Onde os movimentos de corte do açougueiro esculpem na carne o saber que nos alimenta." Em Vaca, o saber que nos alimenta está distante, é, como disse o artista, parte de um processo simbólico. Porque não é uma vaca, nem um pedaço de carne, não há matéria ali para ser conhecida por um contato ou deglutição. Trata-se de gado, algo genérico mas sutilmente particularizado pelo título, obrigando o espectador a entrar e sair do campo discursivo do quadro por conta de outros estratos. E é ai, curiosamente pela disposição formal, que surge o diálogo com Leirner. Porque ainda que não se possa confirmar uma intenção construtiva no aproveitamento de superfícies e matérias dadas na composição do quadro, comenta-se a mesma impossibilidade que se consideraria positiva num contexto modernista de impor a realidade

10. CAGE, John. De Segunda a um Ano (1963), Trad. Rogério Duprat. São Paulo: HUCITEC, 1985, p. 69.

11. PERLOFF, Marjorie. Op. cit, pp. 372- 373: "As imagens que acompanham esse parágrafo (ver figura fig. 6.9) resistem teimosamente ao nosso desejo de torná-las "adequadas" ao texto, pois nada poderia ser menos abertamente sensual ou sexual do que essas áridas extensões de canos, cercadas por areia, entulhos e água estagnada. O efeito deflacionário das imagens fotográficas naturalmente é intencional: Smithson quer que compreendamos que é apenas na imaginação do arista que o monumento Fonte adquire uma vida sexual, assim como os poetas e pinturas futuristas dotaram o simples esqueleto de ferro da torre Eiffel, tanto de uma potencia fálica como de orifícios femininos." 
planar sobre qualquer ilusionismo. Em Vaca, como em Terra/grama/céu ou Terra/ vegetação/céu, o empilhamento ou disposição de estratos cria uma sintagmática vertical ou concêntrica, regular, como se retomasse estruturas reificadas na arte a tal ponto de terem perdido seu sentido. São um ponto médio, intermediário entre a distância e a proximidade, a identificação e o estranhamento, enfim, entre a fruição pela forma ou pelo conceito. No lugar de ironia parece vir um sentido de falência, uma espécie de desenvolvimento de uma tolerância ao formal, um remédio que já não tem efeito ou até um placebo.

Aqui retoma-se a persistência do vetor transversal na trajetória de Tozzi e sua tentativa de neutralizar as distâncias na relação com a imagem técnica e, agora, na relação com o real, pela apropriação. São três as obras de mesmo nome que se pensa a seguir, todas de 1973, duas bidimensionais e um filme em Super 8.

Na primeira, Grama, há a questão da nomeação, do emolduramento, do comentário ao plano virtual da fotografia. Na segunda, retoma-se uma última aproximação entre Tozzi e Oiticica, em relação ao trabalho como Contra - Bólide, devolver a terra à terra (1979):

\footnotetext{
O objeto que não existia passa a existir e o que já existia revela-se de outro modo pela visão dada pelo novo objeto que passou a existir. Está reservada ao artista a tarefa e o poder de transformar a visão e os conceitos na sua estrutura mais íntima e fundamental; é esta a maneira mais eficaz para o homem de hoje dominar o mundo ambiental, isto é, para recriá-lo a seu modo e segundo sua suprema vontade.[12]
}

De acordo com a ideia de Oiticica, a proposição estética supera o objeto. No trabalho de Tozzi em questão, isso também ocorre à medida em que o objeto que passa a existir, no lugar em que encontraríamos o quadro, é dado pela relação objetiva que temos com algo que não representa mais nada, simplesmente é: o chão, o gramado, a grama. É claro que essa relação está colocada, diferentemente do que no caso do Contra-bólide - uma ação com terra e grama, literalmente realizada no chão -, a partir da aproximação frontal com o plano, elemento canônico da tradição pictórica. Mas, é importante insistir na ideia de que Tozzi estava propondo múltiplas aproximações, sinestéticas inclusive, um ambiente, no contexto de proposição dessas suas três obras, partes instaladas, de sua sala na Bienal de Veneza.

Assim, chega-se ao filme Grama. Se no âmbito dos quadros a "obsessão" do artista

12. OITICICA, Hélio. "PARANGOLÉ: uma nova fundação objetiva na arte." In: Ciclo de exposições sobre arte no Rio de Janeiro - 5. OPINIÃO 65. Curadoria Frederico Morais; apresentação Frederico Morais. Rio de Janeiro: Galeria de Arte Banerj, 1985, p. 72. 
pela técnica do zoom chega a um limite fundamental que é a apropriação que viria a transfigurar seu sentido, e se há nesses trabalhos um comentário franco sobre certa impossibilidade de superar o plano ou substituí-lo no campo da experiência das artes plásticas paralelamente a um dilema em relação a certa domesticação da natureza, no campo do cinema, ele encontra uma possibilidade de superação, atravessando de fato o limite do plano e penetrando no "outro lado" da objetiva.

Em um filme que se imagina anterior, Fotograma (1973), a impossibilidade de revelação do conteúdo pela explicitação da matéria no campo da matéria. As mãos do artista não conseguem promover a revelação de uma bobina. Parte-se para o martelo. Quando o invólucro é finalmente destruído, aparece um volume incontinente e dissociado na natureza da mídia técnica. No filme Grama, cuja abertura é feita a partir da filmagem do quadro, está claro que a montagem minimalista sustenta a passagem do olhar para uma realidade de percepção háptica, em um lugar "fenomenológico".

Num percurso paralelo ao do emblemático Wavelength (1967), de Michael Snow, em que a aproximação se dá por cortes explícitos mas que transporta o olhar do espectador do contexto urbano para a paisagem marinha virtual, do real da câmera de circuito interno para a virtualidade da imagem de um tema clássico na história da arte, a montagem, no filme de Tozzi, funciona como uma somatória da perspectiva do objeto, da natureza, da grama, como na metáfora de Deleuze para o expediente de Vertov:

\section{O que faz a montagem é levar a percepção às coisas, colocar a percepção na matéria, de modo tal que qualquer ponto do espaço perceba, ele próprio, todos os pontos sobre os quais ele age, ou que agem sobre ele, por mais longe que se estendam essas ações e reações.[13]}

Ainda assim, nada consegue abolir completamente um processo de identificação que permite, ao fim do filme, que o espectador assista à grama, nessa reciprocidade surrealista, rasteira e monumental, como uma plateia que acena se despedindo.

RAFAEL VOGT MAIA ROSA é doutor em teoria literária pela USP, autor da peça Banhistas (2005) e do roteiro Enquanto estiver aqui (2012).

13. DELEUZE, Gilles. A imagem-movimento, Trad. Eloisa de Araújo Ribeiro. São Paulo: Brasiliense, 1985, p. 